\title{
A SYSTEM FOR REMOTE MONITORING AND CONTROLLING OF DAMS
}

\author{
Zeyana Mohammed Abdullah Al-hadhrami ${ }^{1}$ and Dr.Abdul Khalique Shaikh ${ }^{2}$ \\ ${ }^{1}$ Post Graduate Student, Mazoon University College, Muscat, Sultanate of Oman. \\ ${ }^{2}$ Department of Information Systems, \\ Sultan Qaboos University Muscat Sultanate of Oman.
}

\begin{abstract}
The technological advancement of the current era has affected the processes of the most of the economic and social related businesses. The aims of this advancement are to serve and make human life more comfortable. However, there are still lots of areas in our daily life where manual processes are used. Taking as an example in the water control and management systems, where many authorities use manual systems for water control and management. Especially nowadays most of the countries are still using manual system for controlling and monitoring the dams. Due to the complicated and time consuming process in a manual system, a model for Remote Monitoring and Controlling of Dams is proposed that uses remote control technology, linked to the web technology, to attain great success in monitoring and controlling water levels in managing dams. This paper is to present a new solution which it is to implement a proposed system called as RMCD "Remote Monitoring and Controlling of Dams". With the proposed system it will allow the user to control and monitor the dams remotely which it is saving a lot of efforts, reducing the cost and also increasing the monitoring quality as the users are going to use automated system rather than using of manual system.
\end{abstract}

\section{KEYWORDS}

Software requirements; Requirement management; Requirement engineering; Requirement traceability, Remote Control Application

\section{INTRODUCTION}

A dam is a massive barrier built for the protection of an area from water overflows as well as for use for other reasons such as land irrigation and hydroelectricity generation. Inarguably all countries in the world today have dams. However, a very few operate on automated systems, which are more effective and efficient than manual ones(Arch). Hence, it would be useful for all countries to start to use automatic systems for their dams as this will reduce the amount of effort that they're already putting towards dam maintenance. In addition, the same will help spare the many lives that are often taken by overflow and flood waters, while improving the quality of water supply, etc. It is not only complex to manually control a dam, but also time-consuming and excessively risky in times of bad weather. This is the main reason of why most of the governments and water supply companies today continue to face the problems when it comes to the control management of dams. It would advisable for a country such as Sultanate of Oman to implement the automatic system, where the process will be very easy, for example, replace the

DOI : 10.5121/ijpla.2017.7401 
International Journal of Programming Languages and Applications (IJPLA ) Vol.7, No.2/3/4, October 2017

ineffective manual systems of dam water control and management that it has in place, in favor of an automated one. Given their current use of manual systems, a good number of the countries in the world today continue to face difficulties in terms of:

a. Controlling the levels of water in their dams. The staff is doing the monitoring in manual basis which is too risky, especially in times of bad weather, having led to the loss of lives in some of the countries where it is being practiced. It is suggested to use microcontroller kit with power supply. Microcontroller is a device that read the input, process the operation and write the output (Saranya, Sanhu, Santhiya, Sandhiya \& Palanival, 2016). As a matter of programing, it serves to

b. Monitoring the levels of water in their Dams. The movement of staff to and from dams comes with logistical technicalities that cannot in some cases, be offset by state and private water agencies. This is quite expensive too, tending to sometimes be limited by financial constraints, hence posing a health risk issue.

c. Receiving danger warning and alerts. Manual systems do not have in place any mechanisms that would allow them to make automatic detections when dams come close to overflowing, and this is a health risk issue. The unavailability of alarm systems means that dams do not have an in-built mechanism for sending out warnings when their waters come to dangerously high levels.

\section{Current System}

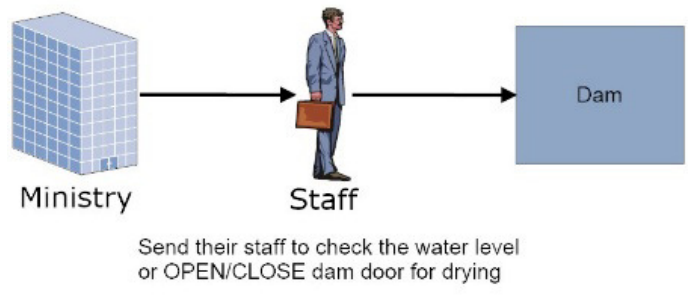

New System

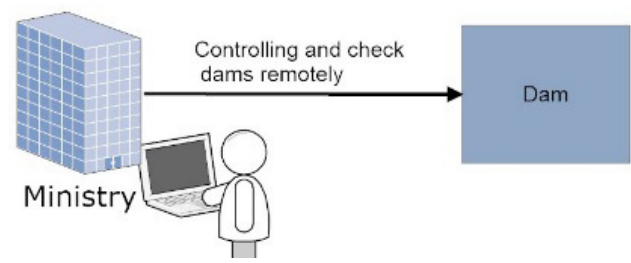

Figure 1: Current System and Proposed System

\section{LITERATURE REVIEW}

The following four research works are closely relevant to our proposed system. Here is the details analysis of each research works: 


\subsection{Embedded Dam Gate Control System}

The project research work (Layer 2013) the embedded Dam Gate Control System is developed. The idea of the project was to develop the proposed system which can control the dams using the embedded system. The Embedded system is the combination of both hardware and software design which contains an automated process that makes easiness for the staff.(Layer 2013). The third project provides information on Controller kit with power supply The fourth project provides information on Motor driver circuit.

Mainly concerned with the real-time operation of dam, we need to consider on the level of water. The embedded system takes action depending on water level. There are different components have been used to implement the proposed system which is (Layer 2013):

\section{a. Sensors with Amplifier:}

This is the first component in which the five sensors related to the water level that is fixed on a PCB, and it made to fix the dam. Whenever the level of water reaches any of this sensor line then the consistent transistor amplifies its input and this data of the sensor is used to trigger the microcontroller (Layer 2013).

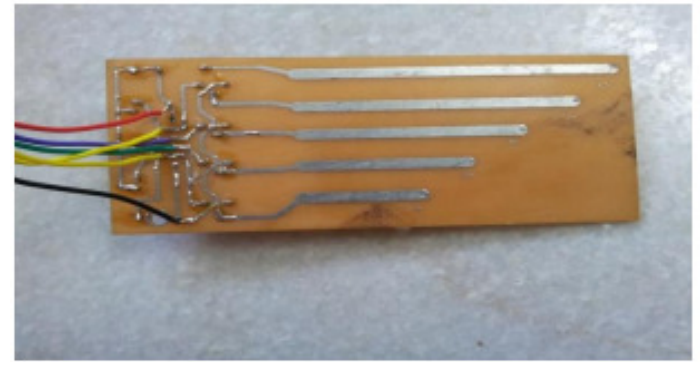

Figure 2: Sensors with Amplifier (Layer 2013)

\section{b. Indication of water level to operator:}

Created with an LCD interface(Wang 2011)that comes connected both to the microcontroller kit and to the control panel at the dam. It was implemented to indicate the frequent changes in water levels at the dams(Layer 2013).

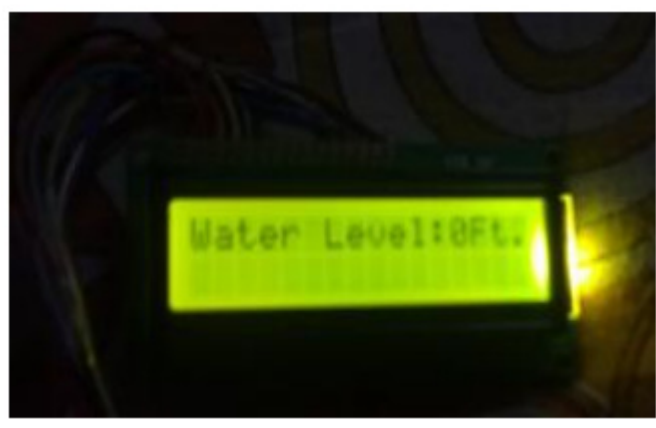

Figure 3: Indication of water level to operator (Layer 2013) 


\section{c. Controller kit with power supply:}

It is referred to the microcontroller kit with power supply. As a matter of programing, it serves to control the dam's gates, also displaying the exact levels of water in the dam at any given time, through an LCD screen (Layer 2013).

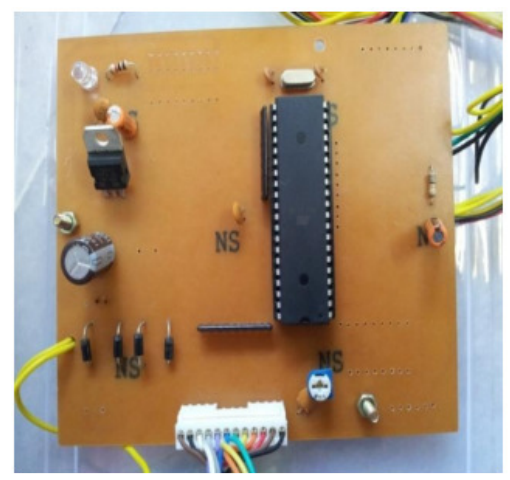

Figure 4: Controller kit with power supply (Layer 2013)

\section{d. Motor driver circuit:}

Operates by making use of four electromagnetic transmits(Wang 2011). Three of these are used, one each for, opening the gate, for closing the gate, and for activating the alarm. The fourth one is left unused, as a spare that could be put into probable future use. Connected to each of these transmits, is an LED that glows in as just as soon as any one of them comes into use (Layer 2013).

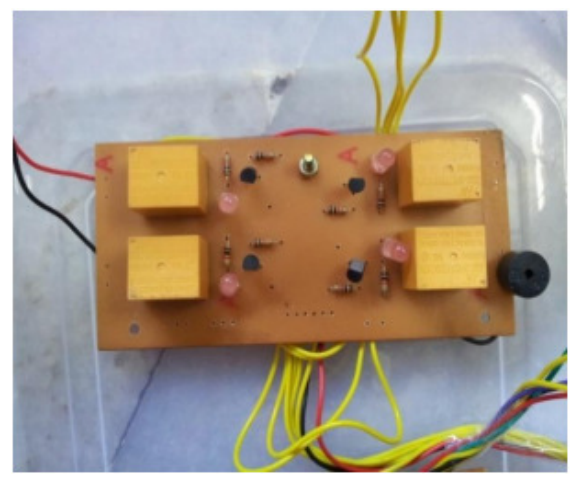

Figure 5: Motor driver circuit (Layer 2013)

\section{e. Dam Gate Arrangement with Motor:}

The last one of the components of this project. Shows an actual arrangement of the model used by the dam to have its gates either opened or closed (Layer 2013). 
International Journal of Programming Languages and Applications (IJPLA ) Vol.7, No.2/3/4, October 2017

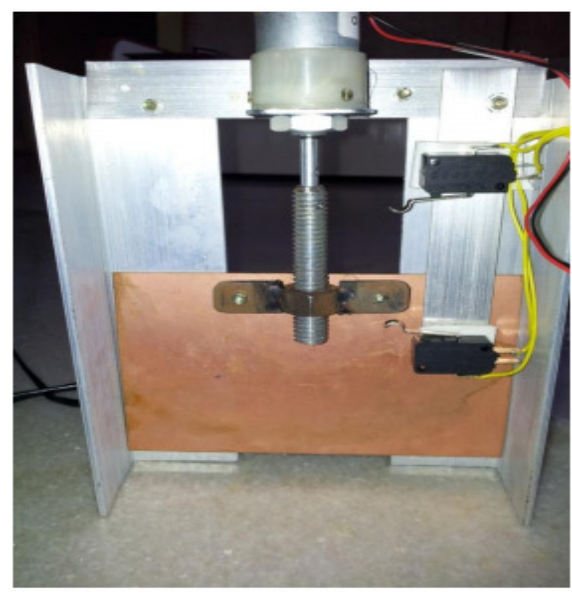

Figure 6: Dam Gate Arrangement with Motor (Layer 2013)

This here below is a flow chart for the proposed system, showing that the two automated gates in the system will have been made to conform with the levels of water that should desirably be held by the dams that they'll be installed at (Layer 2013).

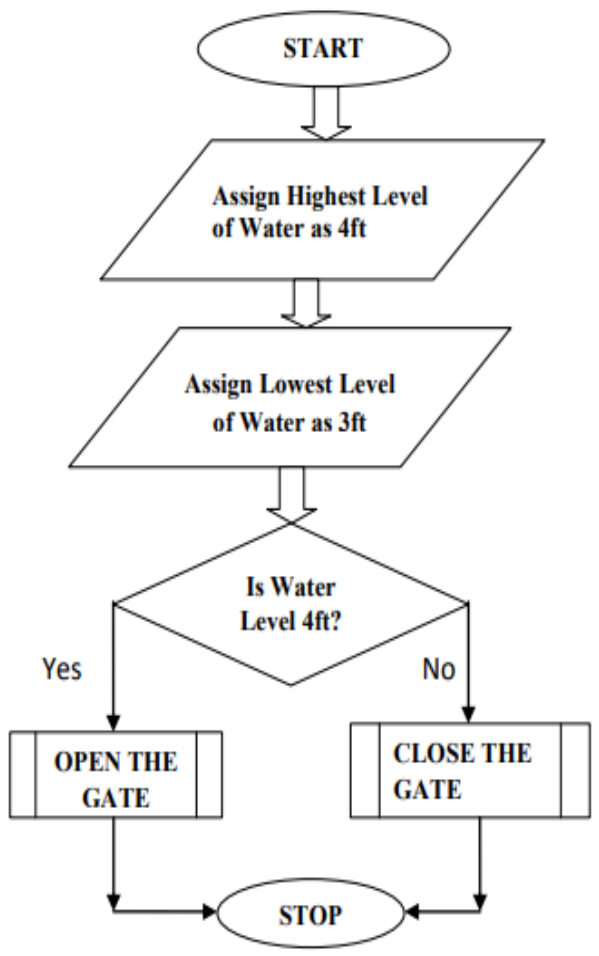

Figure 7: Proposed System Flow Chart(Layer 2013) 


\section{f. Operator Control Panel}

As per the proposal, the control panel can be used to execute only those commands that cannot be supported by the system. Right below is a figure of the control Panel that would have been developed for the system. It comes with a graph in representation of the water levels in the dam, together with an indicator that captures the increases and decreases of these same water levels. The panel also has an AUTO/MANUAL command that allows users to determine whether the gate operates automatically, or with manual facilitation (Layer 2013).

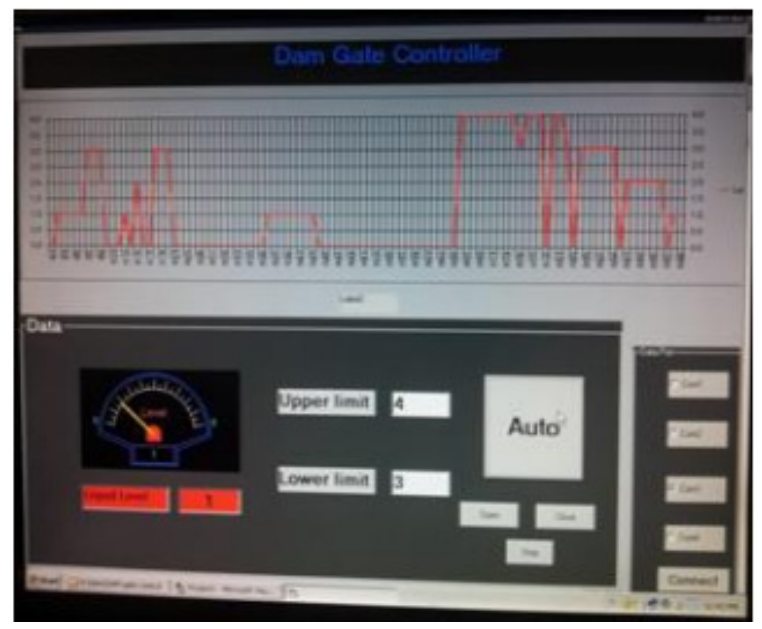

Figure 8: Operator Control Panel Using Visual Studio (Software) (Layer 2013)

\subsection{PLC based Dam Automation System:}

For purposes of this project, PLC based Dam Automation Systems were extensively researched(Sorte 2015). This project was meant to develop an automated system that would help with control and monitoring activities at designated dams, making use of Programmable Logic Controllers (PLC's). A few different components will be used in the implementation of this system. These will be as follows(Sorte 2015):

\section{a. Programmable Logic Controller (PLC):}

This is the main component of the system that's being proposed. It also is the heart of its operations. The PLC offers different Input and Output configurations- 20 inputs and 12 outputs each in total. All of these usually are connected to five micro switches that in turn, will have been interconnected using the Switch Mode Power Supply (SMPS). It is the SMPS that's usually then connected to the system. Ladder Logic software are used for programming the system's logic controllers (PLCs).Below is a block diagram of a system that uses PLC(Sorte 2015). 


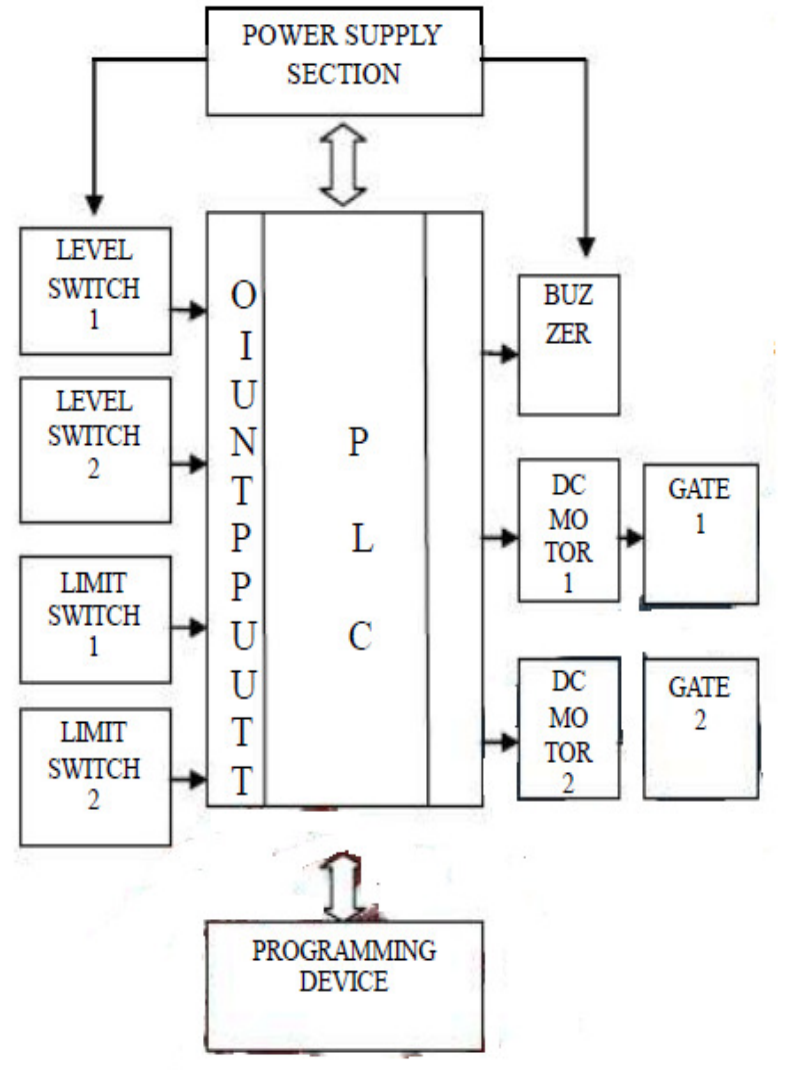

Figure 9: Block Diagram of system using PLC(Sorte 2015)

\section{b. Ensing Element:}

This component is the hollow ball float which it will be fixed to the switch. When the level of the water is increased then this ball will keep floating on the top of the water. Once it is reaching the certain level, then the switch will trigger the PLC's input which controls the action of gates to open the gate in case it is high or close the gate in case it is low(Sorte 2015).

\section{c. Gate Control:}

The proposed system has a total of two gates, Gate 1 which lets initial volumes of water into the dam, and Gate 2 which takes in overflow waters. The water that's let into either one of these two gates first has to have been detected by the level switch. Conversely, the gate is flung open or closed up by the dc motor(Sorte 2015).

\section{d. LED and Buzzer:}

Used to provide the system's users with timely alerts, pointing out that the water levels in any of the dams have reached dangerously high levels. The meaning of an alert here is $a b$ right display on the LED screen, followed up with a distinct sound from the buzzer (Sorte 2015). 


\section{e. Supervisory Control and Data Acquisition (SCADA):}

Picks up data from all of the devices and switches in the system and then displays it on the PC, where it is monitored and also where control decisions can be made. It also is used to provide graphical representations of these two gates as they open and close by motor control. This data is maintained and recorded in a 'login table'(Sorte 2015)

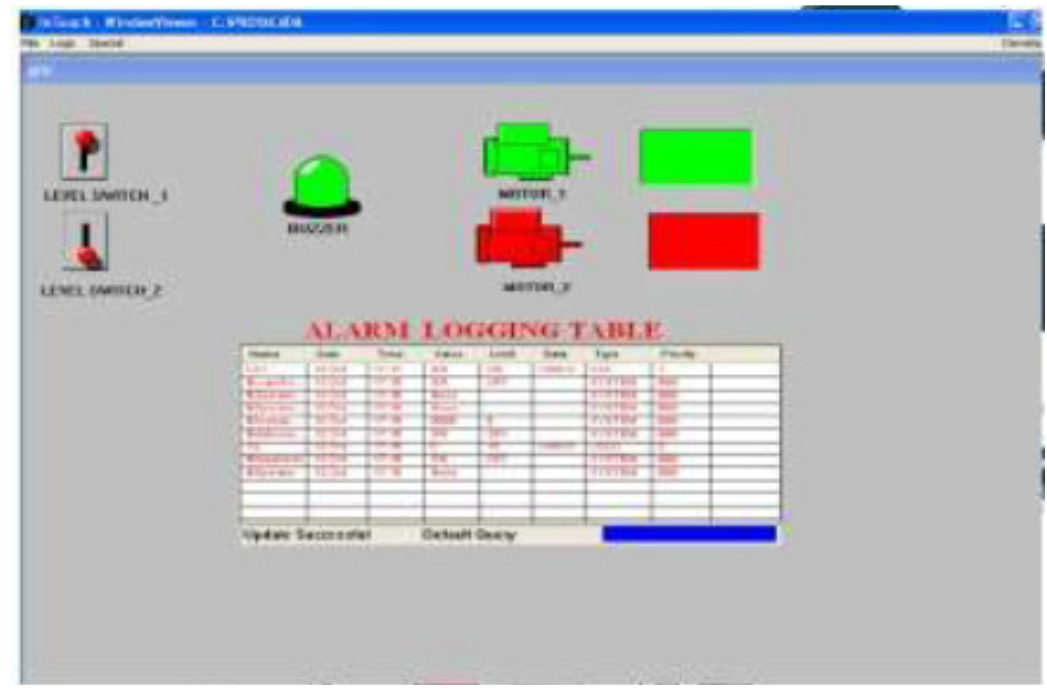

Figure 10: SCADA (Software)(Sorte 2015)

\subsection{Dam Monitoring System Using Wireless Sensor Networks:}

The project research work (Prof.Seema I. 2017) Dam Monitoring System Using Wireless Sensor Networks is to be developed here. The idea behind this project was to develop a system that leaves enough room for the dam to be controlled and monitored from a remote location, using wireless sensor network. (Prof.Seema I. 2017).

The system is fitted with several sensors such as, the Temporary Sensor, the water level sensor, the humidity sensor, the PH sensor and the rain drop sensor. These sensors each take actual results, which then, are conveyed to the microcontroller via a wireless transmitter. The data taken, in turn, may or may not be displayed on the LCD, depending on the ascertained risk level. The sensors work without pausing, making continuous data updates (Prof.Seema I. 2017).

Have been displayed on the LCD, this data then moves on to the RF transmitter. The RF transmitter is used for the transmission of data over long distances. To do this, it usually will engage the use of GSM wireless technology. The transmitted data is gathered at the RF receiver, after which it is passed to the PC. The IOT Application has since been developed for use in updating this data into the Internet. Shown below is a system architecture design for the system(Prof.Seema I. 2017):

Here below is the web page that's been designed for this project. 
International Journal of Programming Languages and Applications (IJPLA ) Vol.7, No.2/3/4, October 2017

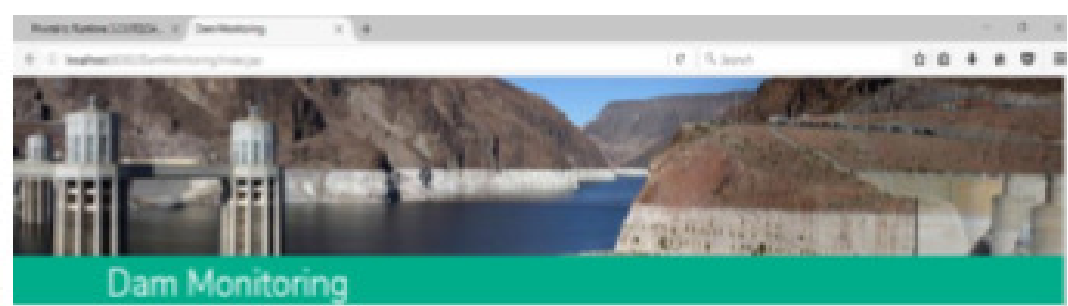

Sensor Data

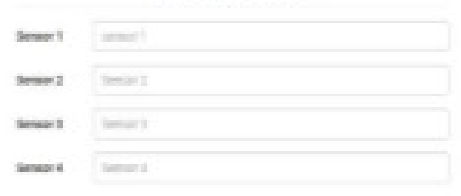

Figure 11: System Architecture(Prof.Seema I. 2017)

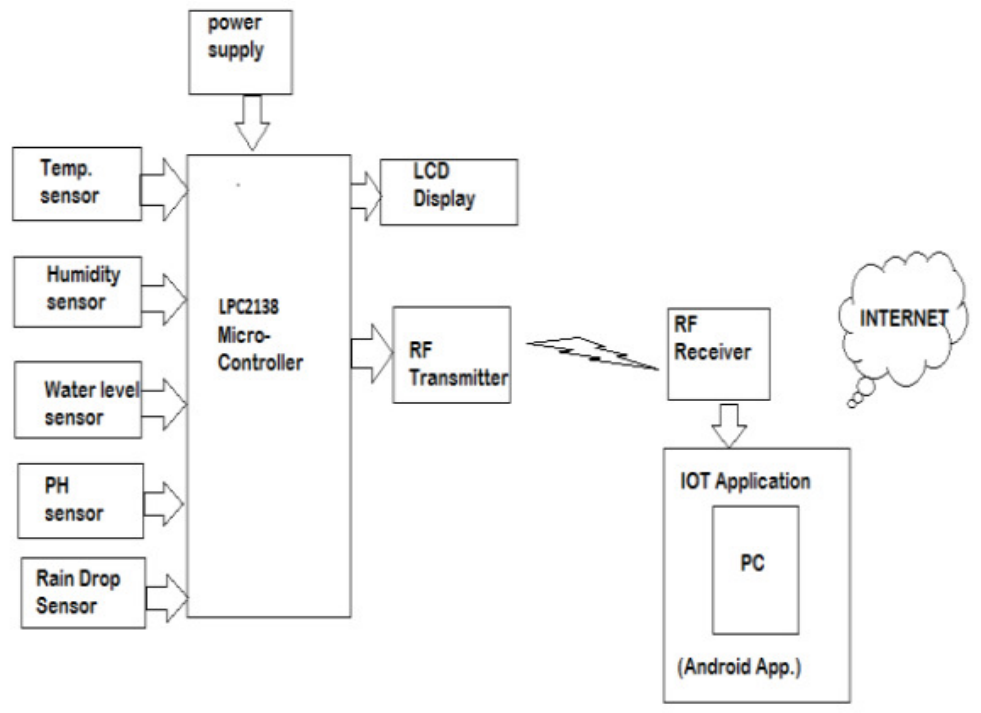

Figure 12: Sensors data for user access (Prof.Seema I. 2017)

\subsection{Dam Data Collection and Monitoring System:}

The project research work (Prof.Seema I. 2017). Dam Data Collection and Monitoring System is developed. The purpose of this project is to develop a system that allows for data to be generated from sensors that will have been fitted at a dam that still, is being monitored to via a site on the web. (Prof.Seema I. 2017).

The proposed system will have several sensors, placed at a dam, which will transfer the data that they obtain to a controller that'll be at a small computer running with the help of GUI software. 
International Journal of Programming Languages and Applications (IJPLA ) Vol.7, No.2/3/4, October 2017

The controller shall be responsible for storing all of the data collected that's hall have been collected with the use of the sensors in the database. This controller will run on the internet, in view of making the monitoring visible at a hosting level that shall have used the web portal. Shown below is the web portal designed for the system:
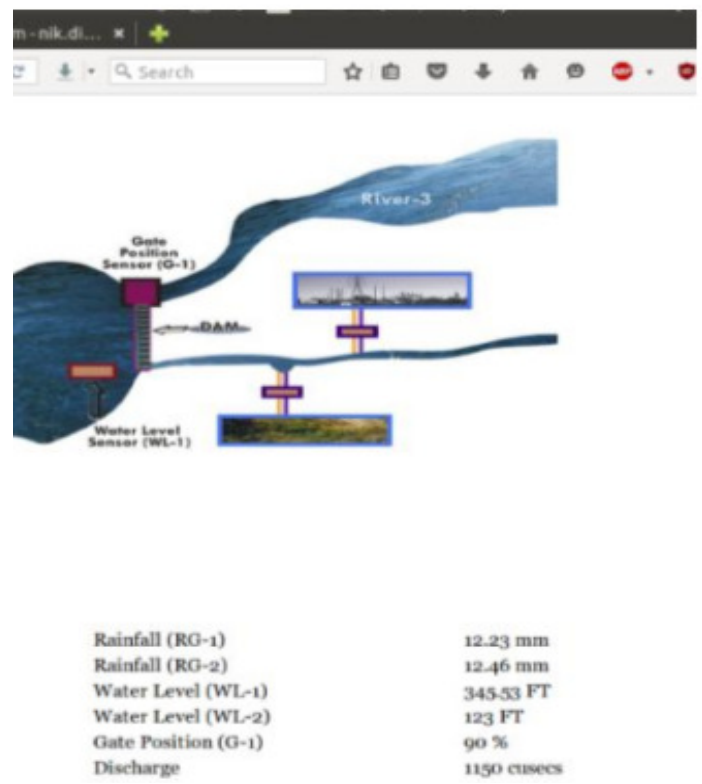

Figure 13: Web-Portal: Dam Parameters(Prof.Seema I. 2017)

Also at the controller, will be analert system that shall monitor water levels to ensure that they never go past the maximum acceptable levels. Below is a sample of an email that could be sent to the system's user:

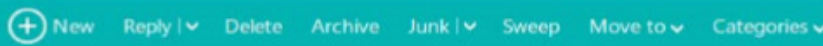

DAM Parameters Report

DWPMS 10:49AM

Dam and Weather Parameter Monitoring System

Report time : 2016-06-20 10:48:56

Temperature $=320 \mathrm{C}$

Humidity $=59.0 \%$

Rainfall $(R G-1)=12.23 \mathrm{~mm}$

Rainfall $(\mathrm{RG}-2)=12.46 \mathrm{~mm}$

Water Level $(W L-1)=345.53 \mathrm{FT}$

Water Level $(\mathrm{WL}-2)=123.0 \mathrm{FT}$

Gate Positon $=90 \%$

Discharge $=1150$ cusec

Figure 14: DAM Parameter Report(Prof.Seema I. 2017) 
International Journal of Programming Languages and Applications (IJPLA ) Vol.7, No.2/3/4, October 2017

\subsection{Comparison of Projects:}

After review of the above projects, it clearly comes out that each of these projects has its advantages and disadvantages as well. By considering the gap of the projects author of the proposed system have realized the following factors that should be available in the system.

- The proposed system should have monitoring screen to allow the user to monitor the level of water in real time system.

- The proposed system should leave its users in control of the gate. Also in place, should be an automated process that opens and then closes the gate depending on preset water levels.

- The proposed system should also have an LED and Buzzer that will bring its users to attention in case the maximum set water level is reached.

- The data should be recorded in real time system, and it will help the user to analyze the water level in future.

The above are the main advantages and good points found during the research. It is observed that these systems also have disadvantage. The weedy thing that most of the systems allow the user to monitor only locally and it is not allowed to the user to control or monitor remotely. By using this approach which it is monitor and control at the dam location, it will have a risk in the user's life, especially during bad weather time. It is highly recommended to have a system which allows the user to monitor and control the dam remotely.

\section{PROPOSED SYSTEM}

The proposed system is about developing an automated system for monitoring and controlling the dams remotely. The proposed system should allow the user the following functionalities:

\section{a. Controlling and monitoring the dams Remotely:}

With the proposed system, the government shall be able to remotely control and monitor her dams. This will eliminate the risks and costs that come with physically monitoring the said dams.

\section{b. Checking and searching for transactions:}

If this system is to be implemented, then government operators will have a far easier time keeping track of transactions at the dam. The system will for example, provide easily retrievable records as to the times when the dam's gate will either have opened or closed. This will both be a cost and human resource effective measure

\section{c. Alerts to be displayed once the water reaches a set maximum level:}

The proposed system will send out timely alerts in the event that the dam nears overflow levels. This will relieve the government from having to monitor the dam round the clock. 
International Journal of Programming Languages and Applications (IJPLA ) Vol.7, No.2/3/4, October 2017

The said alarm will have an operational mechanism that allows it to go off in case the water levels go too high up. This will be very useful for the government.

\section{SYSTEM DESIGN}

This section covers the Use cases, Class diagram, Sequence diagram and Database design

\subsection{Use Cases Diagram:}

Below is a use case diagram, showing the proposed system. From the diagram, it can be seen that, other than the systems users, no one else will have the power to act on it. Also shown, there are five use cases, which means that this user will be at liberty to perform any five main functions of his/her choice. S/he could log into the system, maintain the dams' details, control the dams, check its status and list the history of its use.

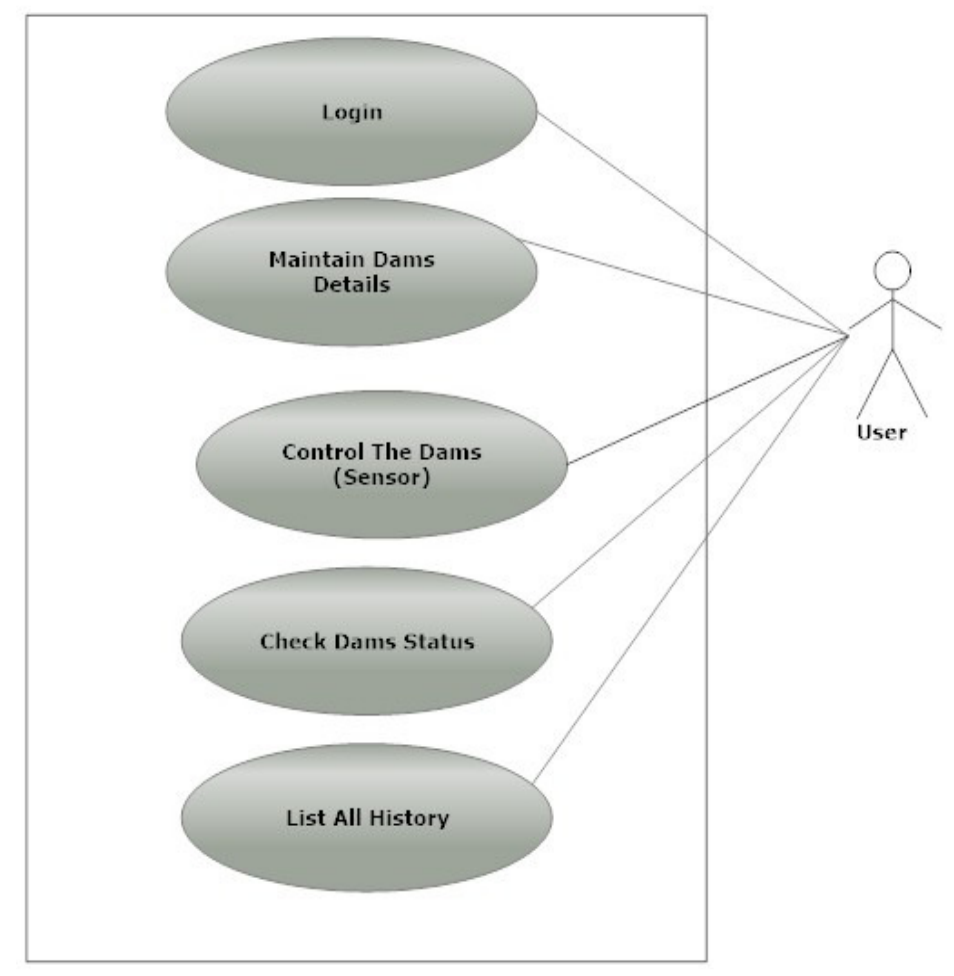

Figure 14: Use Case Diagram

\subsection{Class Diagram:}

Below is a diagram, from class, of the proposed system. Shown in it, are three classes: dams, dam histories and user. 
International Journal of Programming Languages and Applications (IJPLA ) Vol.7, No.2/3/4, October 2017

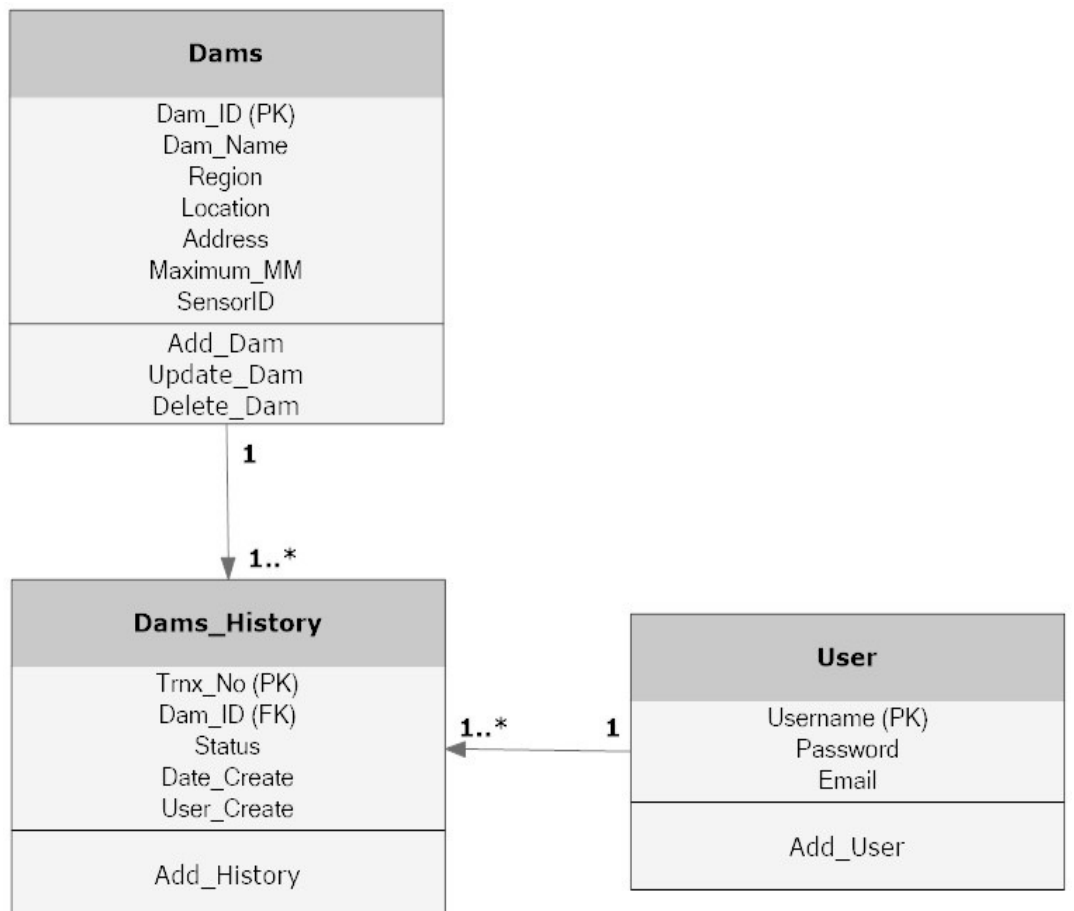

Figure 15: Class Diagram

\subsection{Sequence Diagram:}

Below is the sequence diagram of the proposed system. The sequence diagram shows how the user (object) activates or operates in time sequence. It is shown that the user starts with login, maintains the dams, controls the dams and lists the whole history.

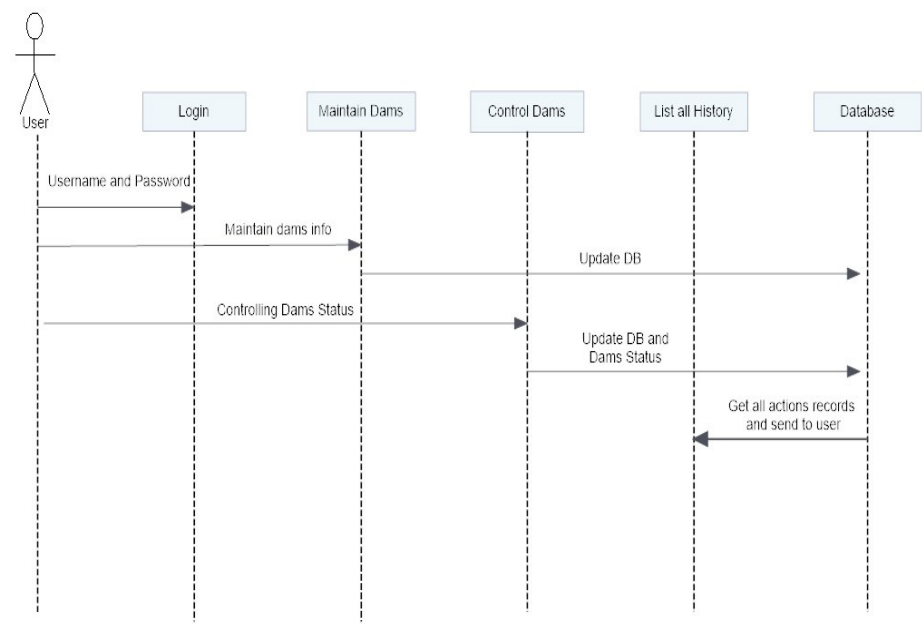

Figure 16: Sequence Diagram 


\subsection{Database Design}

Below is an Entity Relationship Diagram, also showing the proposed system, which shall have three tables, one each for the user, the dams, and the dam histories. The dam table will contain information as to the dams. Their respective histories will be stored, detailing any of the transactions that shall have taken place at their sites. The user table, on the other hand, keeps user information, such as the login details.

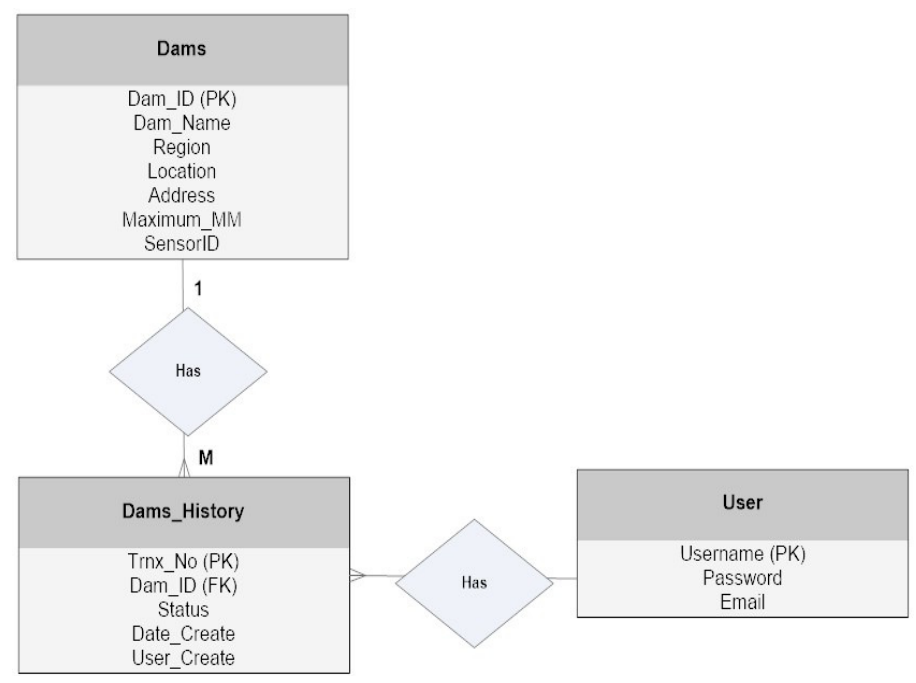

Figure 17: ERD Diagram

\section{PROPOSED SySTEM ARCHITECTURE}

The proposed system is consists of the following components:

a. A Server: Should most preferably be located at the ministry's offices. In it, will be a database for the storage of all transactions at the dam.

b. Thin Client: Each dam will have a thin client, and each thin client will have two sensors.

c. Sensors: The proposed system will have a total of two sensors, which have been shown below. These sensors will have been fixed to the dam, and they both will maintain Bluetooth communication with the thin client.

I. Measuring Water Level Sensor(Vegetronix 2008).

II. Open/Close Sensor to close/open the dam gate. The sensor will be a waterproof sensor(Express).

Below is an architectural diagram of the proposed system, also showing how it shall be working: 
International Journal of Programming Languages and Applications (IJPLA ) Vol.7, No.2/3/4, October 2017

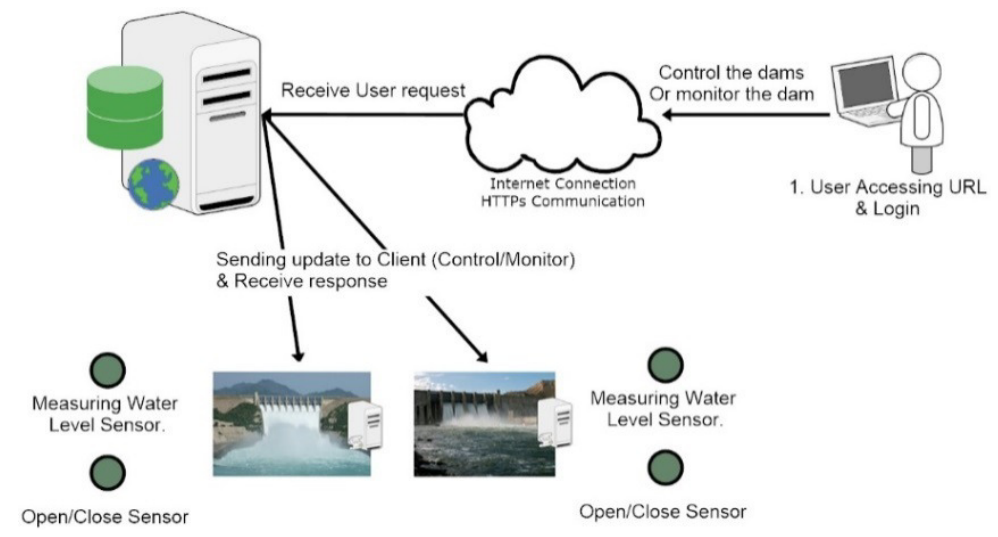

Figure 28: Proposed System Architecture

The above shown figure highlights the architecture that this proposed system shall operate on. Below are further clarifications as to how the proposed system works:

a. HTTPs communication represents the communication that shall keep the server and the thin client in constant communication with each other. This is a secure version of the HTTP (Instances).

b. Any person using the system should have to make use of browser to access the provided UR.

c. Once a user has successfully logged into the system, s/he will be free either to monitor or control the dam.

I. If the user chooses to control the dam, s/he will then have to make a further selection as to the dam that s/he wishes to control. Once this dam has been selected, its status will be shown to the user, allowing him or her to ascertain the levels of water in the dam, together with whether its gate will have been open or closed. A user who wants to change the status shown, say for example, by closing an open door, will do so and then click the update button. Once the update has been made, this information will be picked up by the client, which will communicate it to the sensor via Bluetooth technology, following which the request made will take effect. The client will then send this information to the server, which shall store it in the database.

II. If the user opts to monitor the dam for its water levels, s/he shall click this command into the system via its screen. This screen comes fitted with a real-time system that measures and then shows water levels at the dam once every minute. This screen shall send email alerts, which may come into the viewer's display if the maximum set levels of water are reached at any given dam. All measured data will be stored in the database, together with the times of their measurement. 
International Journal of Programming Languages and Applications (IJPLA ) Vol.7, No.2/3/4, October 2017

\section{SYSTEM IMPLEMENTATION}
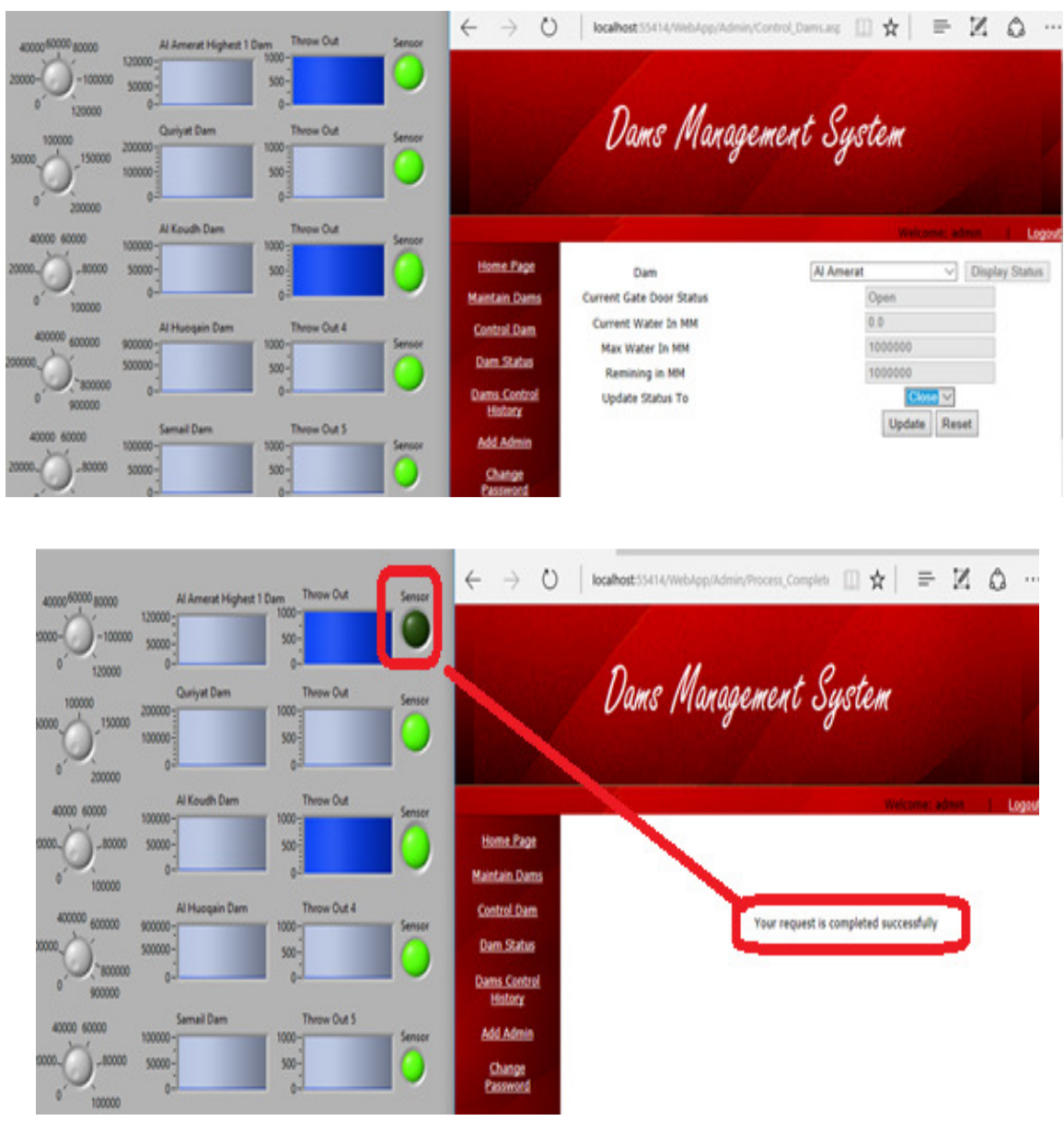

Figure 39: Controlling Dams

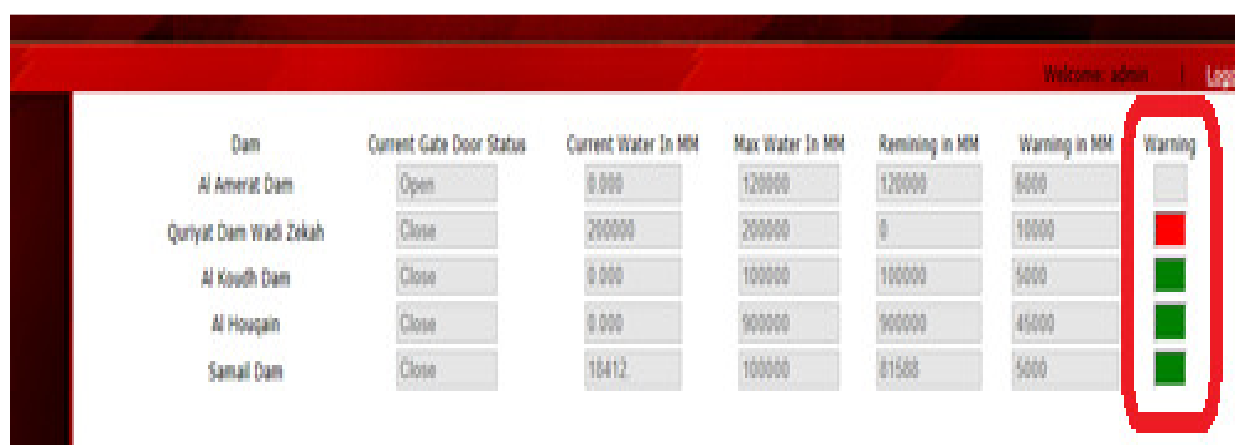

Figure 20: Monitoring Dams 
International Journal of Programming Languages and Applications (IJPLA ) Vol.7, No.2/3/4, October 2017

\section{CONCLUSION}

Since the technology around the world is improving fast, therefore remote monitoring and controlling of dams in Sultante of Oman are being developed. The Different terrain will results to different types of dams regarding height, the quantity of water, access to dams, the process of producing electricity. It is highly suggested and recommended for any countries that they should have few dams for generation of electricity. By using the proposed system, Government will have a facility to reduce complexity in controlling or monitoring the dams as the proposed system use the advance technology to control the dam remotely.

The proposed system has presented to use a thin client and a server application and it has suggested to use HTTPs communication. A real-time system has been used for monitoring screen to monitor the water level at every 1 minute and the alert system has reported to send an email and also display warning in case the water reached maximum level.

\section{REFERENCES}

[1] Travis, J. \& Kring, J. (2006). "Introduction to Graphical Programming with LabVIEW."LabVIEW for Everyone: Graphical Programming Made Easy and Fun, 3rd Edition". Prentice Hall Publisher.

[2] Comodo. (2017) "What is HTTPs?". Retrieved 10/07/2017, 2017, from https://www.instantssl.com/ssl-certificate-products/https.html.

[3] Iyerm M., Pai, S., Badri, S. \& Kharche, S. (2013). "Embedded Dam Gate Control System using 'C' and Visual Basic. International Journal of Computer Applications. Volume 69- No.2, pp 32-37.

[4] Dhandre, N. Jadhav, M. (2015). "Dam Data Collection and Monitoring System." International Journal of Science and Research (IJSR) 5(6).

[5] Idhate, S., Bilapatre, A. Rathod, A. \& Kalbande, H. (2017).. "Dam Monitoring System Using Wireless Sensor Networks." Volume: 04 Issue: 04, pp 1767-1769

[6] Sorte, R., Sonwane, R., Thakur, N., Akhade, S., Kawale, S., Dusawar, R. \& Lalwani, K. (2015). "PLC based Dam Automation System." International Journal of Engineering Research in Electronics and Communication Engineering (IJERECE) Vol 2 - Issue 3.

[7] Vegetronix(2008)."WaterLevelSensors."Available from:https://www.vegetronix.com/Products/AquaPlumb.Accessed Date: 01/07/2017

[8] Feng, L. \& Wang, Y. (2011). "Environmental Effect of Tidal Gate and Measures of Disaster Reduction - A Case Study of the Tidal Gate on Yaojiang River." "5th International Conference on Bioinformatics and Biomedical Engineering, (iCBBE) 2011', Conference Publications, PP 1-4, May 2011.

[9] McGill(2017)."WhatisDam?.",Available from:http://www.arch.mcgill.ca/prof/sijpkes/arch374/winter2001/dbiggs/what.html. . Accessed Date: $01 / 07 / 2017$ 
International Journal of Programming Languages and Applications (IJPLA ) Vol.7, No.2/3/4, October 2017

[10] AliExpress. (N.A.) "Automatic sliding gate Door Open Close presence Sensor/Perimeter active infrared laser beam detector Security bank door sensor.",Available from https://www.aliexpress.com/item/Automatic-sliding-gate-Door-Open-Close-presence-SensorPerimeter-active-infrared-laser-beam-detector-Security-bank/32784911081.html. Accessed Date: 01/07/2017

[11] Saranya, B., Sanju, S., Santhiya, L.P., Sanhiya \& G., Palanival, D. (2016). Automatic Gate Control and Monitoring the Water Reservoit using GSM Technology. IJRE - International Journal of Research in Electronics.Volume: 03, Issue: 03, pp 34 - 36.

[12] Yuvarani, T. \& Archana, R., (2016), Water Level Monitor, Control and Alerting System Using GSM In Dams and Irrigation System based on Season . International Journal of Scientific \& Engineering Research. Volume 7, Issue 4, April-2016, pp 135 - 137.

[13] Saranya.B, Sanhu.S, Santhiya, L., Sandhiya, G. \& Palanival, D. (2016). Automatic Gate Control and Monitoring the Water Reservoir using GSM Technology. IJRE - International Journal of Research in Electronics. Volumne: 03, Issue: 03 